\title{
Para uma genealogia da recepção de Novas Cartas Portuguesas em França
}

\author{
Adília Martins de Carvalho \\ Universidade do Luxemburgo/ ILCML
}

Resumo: À semelhança do projecto internacional “Novas Cartas Portuguesas: 40 anos depois”, que celebrou as quatro décadas após a publicação da obra em 1972 e o fim do processo em 1974, em França foram múltiplos os estudos, livros, conferências e diversas actividades, que em 2010 comemoraram os 40 anos do MLF (Mouvement de Libération des Femmes). Qual a relação existente entre as manifestações públicas que permitem balizar a origem do MLF, em 1970 e as acções de apoio às "Três Marias" e divulgação das Novas Cartas Portuguesas, que tiveram lugar em Paris, entre Março de 1973 e Setembro de 1974 ? Se prestamos uma especial atenção a este momento da história do feminismo em França é porque algumas das protagonistas dos acontecimentos considerados como marcos do nascimento do movimento de libertação das mulheres, nesse país, estão intimamente ligadas às principais acções de apoio às três escritoras portuguesas, que aí ocorreram.

Palavras-chave: feminismos, movimento, libertação, mulheres, Novas Cartas Portuguesas, França

\begin{abstract}
The international project "New Portuguese Letters: 40 years later" commemorated the 40th anniversary of the publication of the eponymous book in 1972 and the end of the court trial in 1974. Likewise in France, numerous books, studies, conferences and various manifestations in 2010 celebrated the birth of MLF (Mouvement de Libération des Femmes) forty years before. To what extent can it be argued that there is a relation between the public actions that came with the origin of MLF, and the support that was organized in Paris between March 1973 and September 1974 in favour of the "Three Marias" and of the disclosure of New Portuguese Letters? The reason why our attention has been drawn to this period in the history of French feminism is that some protagonists of the founding events of MLF in that country also gave their full support


to the Portuguese "Three Marias".

Keywords: feminisms, movement, liberation, women, New Portuguese Letters, France

ao Pedro Palma,

camarada que deixou uma grande saudade a todos que com ele viveram em Évora.

O projecto "Novas Cartas Portuguesas 40 anos depois", no âmbito do qual foi realizado na Universidade de Évora de 13 a 15 de Março de 2014 o colóquio internacional, "Novas Cartas, Novas Cartografias: Re-configurando Diferenças no Mundo Globalizado", manifesta, a meu ver, traços análogos a uma série de acontecimentos que tiveram lugar em França em 2010 com o intuito de marcar os 40 anos do MLF: Mouvement de Libération des Femmes. Se o referido projecto celebra as quatro décadas passadas após a publicação da obra, em 1972, e o fim do processo, em 1974, em França foram múltiplos os estudos, livros, conferências e diversas as actividades que comemoraram em 2010 os 40 anos do Movimento de Libertação das Mulheres.

O livro, Génération MLF: 1968-2008, publicado pela editora “Des Femmes-Antoinette Fouque”, em 2008, começa com a seguinte frase: "Le MLF a quarante ans" (Fouque 2008: 7). Esta e muitas outras afirmações provocaram no meio feminista francês, sobretudo nos elementos da geração de 68, uma discórdia relativamente à origem e à data de formação do movimento. Face a tal discordância, foi criada a associação, "40 ans de MLF”, cuja função seria a de restabelecer os factos que justificam o nascimento do movimento em 1970 e consequentemente comemorar oficialmente os seus 40 anos em 2010.

Se refiro esta comemoração francesa é sobretudo porque algumas das protagonistas dos acontecimentos considerados como marcos do nascimento do movimento de libertação das mulheres, em França, em 1970, estão directamente ligadas aos acontecimentos que 
marcaram a recepção das Novas Cartas Portuguesas e o apoio às “Três Marias”, em França, entre Março de 1973 e Setembro de 1974.

Foram essencialmente três as acções de apoio às "Três Marias, que tiveram lugar em Paris.

A primeira consistiu na entrega de um abaixo-assinado, de apoio às três Autoras, na Embaixada de Portugal, a 3 de Julho de 1973, no seguimento da Conferência Internacional da NOW, National Organization of Women, que teve lugar em Boston, entre 3 e 5 de Junho de 1973. Aquela que ficou conhecida como a causa das "Três Marias", foi divulgada nesta conferência pelas brasileiras Gilda Grillo, Danda Prado, Mariza Figueiredo e a americana Faith Gillespie. A essa ocasião Gilda Grillo apresentou a primeira leitura pública internacional de extractos de Novas Cartas Portuguesas; e segundo o seu testemunho esta acção foi fortemente encorajada por Danda Prado. ${ }^{1}$ Quando nessa conferência a causa das "Três Marias" se constituiu como a primeira causa feminista internacional, foi decidido que, na véspera ou no próprio dia de cada audiência do julgamento, uma acção de apoio às três autoras e de contestação ao processo que lhes tinha sido instaurado teria lugar nos diversos países de origem das feministas participantes na Conferência Internacional, que teriam sido à volta de quatrocentas. 0 texto do abaixo-assinado que foi entregue na Embaixada de Portugal em Paris² e que antecede os nomes e as assinaturas é o seguinte: "Nous les femmes de diverses nationalités nous protestons contre le procès qui a été intenté à Isabel Barreno, Teresa Horta e Maria Velho da Costa." [Nós, mulheres de diversas nacionalidades protestamos contra o processo instaurado a Isabel Barreno, Teresa Horta e Maria Velho da Costa.]

A segunda acção consistiu na Leitura-Espectáculo intitulada "La Nuit des Femmes" realizada na noite de 21 de Outubro de 1973, na sala Gémier do Palais de Chaillot. No cartaz que anuncia o evento, visível no documentário sobre o acontecimento, intitulado Les trois portugaises ou Les trois Marias [As três portuguesas ou As três Marias], realizado pela actriz feminista Delphine Seyrig com a colaboração de Carole Roussopoulos e Iona Wieder ${ }^{\text {, lê-se }}$ «Delphine Seyrig / Isabelle Ehni / Ruth Escobar / lisent des textes interdits des trois marias menacées d'emprisonnement pour avoir écrit les nouvelles lettres portugaises» [Delphine 
Seyrig / Isabelle Ehni / Ruth Escobar / lêem textos proibidos das três marias, ameaçadas de prisão por terem escrito as novas cartas portuguesas].

A terceira acção consistiu na "Procissão"/ Manifestação Nocturna, diante da catedral de Notre-Dame de Paris, a 30 de Janeiro de 1974. Assim, servem de testemunhos directos destas três acções, o abaixo-assinado entregue na Embaixada de Portugal em Paris, que se encontra no Arquivo Histórico do Ministério dos Negócios Estrangeiros em Lisboa, o vídeo do espectáculo "La nuit des femmes", intitulado "Les trois Maria ou Les Trois Portugaises", de autoria de Delphine Seyrig, que se encontra no Centro Audiovisual Simone de Beauvoir, em Paris, e as fotografias de Irène Bouaziz, uma das manifestantes, da procissão/manifestação noctuna, diante de Notre-Dame. ${ }^{4}$

Atente-se agora aos marcos do nascimento do Mouvement de Libération de la Femme e à sua relação com os acontecimentos que marcaram em França o apoio às "Três Marias".

Martine Storti, presidente da Associação "40 ans du MLF" criada para celebrar a efemérides, Françoise Picq, autora da obra de referência sobre o MLF intitulada "Libération des femmes: les années-mouvement" (1993), reeditada em 2011 com o título "Libération des femmes 40 ans de mouvement", e Christine Delphy, investigadora na área da sociologia do Centre National de Recherche Scientifique, fundadora da revista Questions Féministes que deu posteriormente origem a Nouvelles Questions Féministes (Cf. infra), apontam três momentos fortes, colectivos e públicos que ocorreram em 1970, tornando-o "ano zero" do Movimento de Libertação das Mulheres em França.

E esses três momentos, por ordem cronológica, são os seguintes:

O primeiro foi a publicação do artigo "Combat pour la libération de la femme", escrito por Monique Wittig, mas também assinado por Gille Wittig, Marcia Rothenburg e Margaret Stephenson no jornal L'Idiot International, em Maio de 1970.6 Este longo artigo que tinha como título original: "Pour un mouvement de libération des femmes", no plural, acaba por ser publicado com o título "Combat pour la libération de la femme", no singular, contrariamente à vontade das suas signatárias.

O segundo foi a acção simbólica de depor uma enorme coroa de flores, sob o arco do 
triunfo, em memória da mulher do soldado desconhecido, a 26 de Agosto de 1970. Esta manifestação levada a cabo por nove mulheres e organizada em solidariedade com a greve das feministas americanas, ${ }^{7}$ dará origem à existência mediática do movimento feminista de segunda vaga em França. No dia seguinte, a imprensa anuncia o nascimento do "Movimento de libertação da mulher francesa". ${ }^{8}$ Esta denominação da imprensa vai causar uma grande polémica devido, à generalização do termo "mulher", pois uma grande parte das feministas reivindicará a pluralização do termo por este significar precisamente a diversidade das mulheres e não a sua clausura no estereótipo "A mulher". As manifestantes são: Cathy Bernheim, Monique Bourroux, Frédérique Daber, Christine Delphy, Emanuèlle de Lesseps, Christiane Rochefort, Janine Sert, Monique Wittig e Anne Zelensky (Delphy 1991: 143), e transportam faixas com duas frases que se tornaram conhecidas pela sua irreverência: "Un homme sur deux est une femme" [Um em cada dois homens é uma mulher] - expressão que antecipa a futura crítica feminista a um discurso pseudo "neutro" ou geral que apaga e esquece as mulheres - e a frase: "Il y a plus inconnu que le soldat inconnu - SA FEMME" [Há mais desconhecido do que o soldado desconhecido: A SUA MULHER]. E na faixa sobre coroa de flores lia-se: “À la femme inconnu du soldat / Les femmes en lutte" [À mulher desconhecida do soldado / As mulheres em luta]. Este acontecimento, geralmente considerado como "simbolicamente" fundador, reflecte, através da sua inventividade, exultação e insolência, características fundamentais do M.L.F, principalmente nos seus primeiros anos, sendo estes habitualmente considerados até meio da década de 70.

O terceiro acontecimento é a publicação do número especial da revista Partisans, intitulado "Libération des femmes année zero", em Novembro de 1970. Escrevem neste número Emmanuèle (de Lesseps), Christine Dupont (Delphy), Anne et Jacqueline (Zelenski/Feldman-Hogasen), sendo as quatro fundadoras do grupo feminista FMA (Féminisme, Marxisme, Action). Os nomes entre parênteses, devem-se à identidade não assumida pelas autoras dos textos publicados neste número da revista. É bem possível que as autoras de Novas Cartas Portuguesas tenham lido este número especial de Partisans, uma vez que na Carta de uma universitária de Lisboa de nome Mariana a seu noivo (?) António em parte incerta, há uma referência implícita a François Maspero, editor desta revista de 
esquerda. Maspero não só é editor como também é proprietário da livraria parisiense, $L a$ Joie de Lire, evocada nessa carta (Barreno/Horta/Costa 2011: 189).

A partir destes acontecimentos "fundadores", em Outubro de 1970, as Assembleias Gerais constituídas apenas por mulheres começam a realizar-se na Escola de Belas-Artes em Paris. $O$ direito ao aborto tornar-se-á a reivindicação principal, que permitirá ao MLF existir na cena política. As primeira acções e os primeiros textos publicados colectivamente pelo MLF, dão uma especial importância à despenalização do aborto, esta questão ocupará, aliás um lugar privilegiado no referido número de Partisans : "Libération des femmes année zero" (1970). Esta publicação ao teorizar a questão do aborto numa perspectiva feminista, propõe, segundo Bibia Pavard, "une lecture non plus centrée sur les problèmes de santé publique, mais sur la domination masculine et de la nécessité de la femme de s'en libérer" (Pavard 2012: 137) [uma leitura não centrada nos problemas de saúde pública, mas na dominação masculina e da necessidade da mulher desta se libertar].

A primeira publicação do Torchon Brûle (n.o 0) surge como suplemento do primeiro número do L'Idiot International e é produzido colectivamente pelas militantes do MLF, tal como os seguintes. O Torchon Brûle é considerado como o jornal porta-voz do movimento e foi publicado de Dezembro de 1970 (n. ${ }^{\circ}$ 0, suplemento do L'Idiot International) a Junho de 1973, num total de oito fascículos (contando o n.o 0 e o suplemento do n.ำ 6, intitulado "Fête des mères"). Durante os seus dois anos de vida, este jornal dedicou várias páginas às questões relacionadas com o aborto e a contracepção. 0 manifesto das 343 mulheres que declararam ter abortado, publicado na revista Nouvel Observateur em Abril de 1971, será de facto a acção que consagrará a existência política do MLF (idem: 138). ${ }^{9}$

Perante os três momentos "fundadores" do MLF e as três acções de apoio às "Três Marias", a questão que se coloca é a de saber qual a relação entre estas três manifestações públicas que permitem balizar a origem do MLF, e as três acções de apoio às três Autoras de Novas Cartas Portuguesas e à respectiva divulgação da obra em França?

Como refere Christine Delphy no seu artigo, "Les origines du Mouvement de Libération des Femmes en France”, «Tout ce que l'on peut dire d'un mouvement, c'est qu'il a des origines, et qu'à ces origines, on peut effectivement identifier certaines personnes (mais 
pas nécessairement toutes)» (Delphy 1991: 138) [Tudo o que se pode dizer sobre um movimento é que este tem origens, e que nessas origens pode-se de facto identificar algumas pessoas (mas não necessariamente todas)]. Ora, o que se verifica é que algumas das protagonistas, que intervieram nos acontecimentos que acabámos de referir, participam activamente nas três principais acções de apoio às "Três Marias" e na primeira publicação do livro no estrangeiro. Cinco das nove participantes na acção dita simbólica da emergência do MLF, a coroa de flores levada ao Arco do Triunfo em Homenagem à Mulher do Soldado Desconhecido, estão directamente ligadas às três iniciativas de apoio às "Três Marias", assim como à difusão do seu livro. E as cinco participantes são Christiane Rochefort, Monique Wittig - duas escritoras já reconhecidas na época - Christine Delphy (cf. supra),10 Dominique Bourroux e Cathy Bernheim.

A ligação destas cinco feministas com as acções de apoio às autoras e à difusão do livro resulta da chegada de um exemplar a casa de Christiane Rochefort, que a partir daí chega ao núcleo das feministas revolucionárias. Rochefort será uma das colaboradoras da publicação "Libération de la femme : année zéro", com o texto: "Le mythe de la frigidité féminine", tal como Christine Delphy11, com o texto "L'ennemi principal”.

Segundo o prefácio de Monique Wittig e Evelyne Le Garrec à edição francesa de Nouvelles Lettres Portugaises, teria sido porque as suas autoras leram dois artigos de Christiane Rochefort, nesse número especial de Partisans, que a escolheram como destinatária da obra proibida. Curioso é o facto de nesse número Christiane assinar apenas um artigo, sendo no entanto possível que tivesse escrito outro anónimo, uma vez que há vários textos colectivos sem a identificação das suas autoras nessa publicação. Dos três livros e respectivas cartas que, segundo Maria Teresa Horta ${ }^{12}$ e Maria Isabel Barreno ${ }^{13}$ foram enviados a Simone de Beauvoir, Marguerite Duras e Christiane Rochefort, até hoje só se conhece o destino de um, o que chegou a casa de Rochefort, em Março de 1973 (Le Garrec / Wittig 1974: 7). Apesar de só ser conhecido o destino de um livro não deixo de considerar na minha pesquisa a ligação de Simone de Beauvoir e Marguerite Duras ao M.L.F; não só por serem destinatárias do livro, mas também pelo facto dos seus nomes constarem do abaixo-assinado entregue na Embaixada de Portugal em Paris. No entanto, 
não cabe aqui desenvolver este aspecto. Monique Wittig, uma das tradutoras da obra para língua francesa é precisamente uma das primeiras pessoas a tomar contacto com o livro, enquanto membro do grupo de consciência ao qual este chega pela mão de Cármen Sanchez. ${ }^{14}$

Monique Wittig assina o abaixo-assinado entregue na embaixada de Portugal a 3 de Julho de 1973, aliás como Christine Delphy, e vêmo-la ainda no vídeo realizado a partir de imagens captadas no espectáculo "La nuit des femmes" no Palais de Chaillot. Neste mesmo vídeo intitulado Les Trois Portugaises ou Les Trois Maria, de autoria de Delphine Seyrig, é identificada outra participante da acção do Arco do Triunfo, Monique Bourroux. Foram três militantes, dos inícios do MLF, que tive a oportunidade de conhecer que identificaram Monique Wittig, Dominique Bourroux e Gilda Grillo, neste vídeo. As militantes com quem conversei foram Dominique Poggi, socióloga, interveniente no espectáculo "La nuit des femmes", signatária do abaixo-assinado e manifestante na procissão no adro de Notre Dame de Paris, Josy Thibaut, que tem actualmente 91 anos e é considerada no meio feminista francês como uma figura histórica do movimento, e Catherine Deudon, fotógrafa ligada ao MLF desde os seus inícios, signatária do abaixo-assinado e manifestante da mesma procissão. ${ }^{15}$ Josy Thibaut ao manifestar na procissão nocturna, no adro da catedral de Notre-Dame, aparece, juntamente com Dominique Poggi, na fotografia do artigo "Les trois Marias" publicado na revista Le Nouvel Observateur, a única que na época saiu na imprensa e que pode ser vista na página web do projecto "Novas Cartas Portuguesas: 40 anos depois".16

Estas três militantes aparecem nas fotografias tiradas por Irène Bouaziz ${ }^{17}$, durante a manifestação diante da catedral de Notre Dame, mas também numa outra série de fotografias tiradas a um grupo mais íntimo, num café das imediações, a seguir à manifestação. Em ambas as séries vêem-se Monique Wittig, Gilles Wittig, Marie-Jo Bonnet, Catherine Deudon, Josy Thibaut, Dominique Poggi, Liliane Kandel e Cathy Bernheim.

Todas estas figuras se encontram implicadas nas acções dinamizadas pelas feministas radicais do $M L F,{ }^{18}$ que preferiam a denominação de revolucionárias por terem a 
sua própria revolução a levar a cabo: a da luta contra o patriarcado, como anunciam no texto panfletário "Féministes Révolutionnaires", publicado no n.o 5 do Torchon Brûle.

A tradução de Novas Cartas Portuguesas em francês e a respectiva publicação na colecção “Combats" das Edições du Seuil, em Setembro de 1974, a primeira no estrangeiro, resulta, provavelmente, muito mais do empenho de Monique Wittig, que da editora; mesmo se Claude Durand, director da colecção, manifestava um grande interesse por obras revolucionárias, publicando entre outros autores, Herbert Marcuse e Régis Debray. Aliás, segundo o breve contacto que tive, através de correspondência electrónica com o editor, Claude Durand, o livro ter-lhe-ia chegado às mãos, já traduzido, através de Monique Wittig ou de uma amiga brasileira que lhe teria sido apresentada por Régis Debray. Num email que me foi enviado por Claude Durand, a 27 de Janeiro de 2014, constam as seguintes informações:

Chère Madame,

Je vous remercie de votre message relatif aux Nouvelles Lettres portugaises publiés en français dans la collection Combats que je dirigeais alors au Seuil.

Je vous avoue que, 40 ans après, ma mémoire ne me permet pas de répondre avec grande précision à votre demande. J'ai souvenir que le manuscrit m'est parvenu déjà traduit et ce, magnifiquement. Me fut-il transmis par Monique Wittig, auteur de Jérôme Lindon, rendu célèbre par son Opoponax paru aux Éditions du Minuit, ou bien me fut-il recommandé par une amie brésilienne que m’avait présentée Régis Debray? Mes souvenirs là-dessus sont confus. Une chose est sûre: c'est au moins autant l'extrême qualité littéraire que l'inspiration féministe qui emporta ma décision. Je crois me rappeler que l'accueil critique fut chaleureux dans la presse de gauche et que les ventes furent honorables.

Passados 40 anos o editor já não se lembra bem das circunstâncias. No entanto, na sequência das pesquisas que posteriormente realizei no IMEC (Institut Mémoires de l'édition contemporaine) e, em função dos contratos de tradução celebrados pelas edições du Seuil, aí encontrados, tudo leva a crer que teria sido através da amiga brasileira apresentada por Régis Debray, que o editor tomou contacto com a obra e que nessa altura esta não estaria ainda totalmente traduzida. Aliás, como sugere Françoise Picq no seu já referido livro-referência sobre o $\mathrm{MLF}^{19}$, a publicação de Nouvelles Lettres Portugaises nesta 
editora será objecto de crítica no meio feminista. A crítica dirige-se àquelas que confiaram a obra a um editor capitalista e não a uma editora feminista, subentendendo-se aqui a editora des Femmes. Françoise Picq refere assim o desentendimento entre o grupo da editora des femmes e outras feministas francesas:

Mais la rupture est consommée avec les féministes françaises, qui préfèrent publier leurs livres collectifs ou individuels - chez d'autres éditeurs (Le livre de l'oppression des femmes publié en 1972 chez Belfond, Maternité esclave sort en 1975 dans la collection "10/18".) (...) Il y a aussi celles qui préfèrent "les bonnes vieilles traditions patriarcales", qui collaborent avec Giscard-Giroud, qui publient des livres chez des éditeurs capitalistes ou bien qui confient à ceux-ci le livre des trois Marias. (Picq 1993: 214-215)

Será importante lembrar que a editora des femmes, emergente no mesmo ano da edição francesa das Novas Cartas Portuguesas (1974), era dinamizada pelo grupo Psychanalyse et Politique, mais conhecido pelo diminutivo Psychépo, e tinha como líder Antoinette Fouque, cujas ideias sobre o feminismo se opunham diametralmente à tendência feminista radical/revolucionária da qual Monique Wittig era uma das activistas principais.

Desde as suas origens que no seio do MLF germinaram "tendências" opostas e diferentes agrupamentos, cada um com as suas ideias e teorias específicas, dando origem a cisões frequentes no seu seio ${ }^{20}$. No entanto duas "tendências" maiores deixaram a sua marca na história recente do feminismo francês, a do feminismo radical e revolucionário, inspirada n'O Segundo Sexo de Simone de Beauvoir, e a tendência diferencialista. A primeira defende que as definições de género, as categorias de "masculino" e "feminino", sempre foram fabricadas nas sociedades patriarcais com o objectivo de manter essa mesma ordem social; explicando que a percepção das mulheres como seres naturalmente diferentes dos homens serve apenas para justificar a opressão masculina. Uma das intenções fundamentais desta tendência é a revolução não contra o capital mas contra o patriarcado, como é sugerido num dos seus textos primeiros, "L'ennemi principal” de Chrsitine Delphy. Para esta teórica do feminismo materialista, o patriarcado não seria um sub-produto do capitalismo mas um modo de produção em si mesmo, apoiado na exploração das mulheres através do trabalho 
doméstico. A grande vantagem desta teoria seria a de sublinhar o denominador comum das mulheres apesar das diferenças sociais. Não o denominador comum da natureza biológica, mas o da sua situação social (Picq 1993: 199).

As feministas radicais e revolucionárias do MLF denunciam assim uma opressão específica das mulheres e a necessidade de lutar prioritariamente contra o patriarcado. Esta perspectiva exprime-se desde 1970, nos já referidos artigos de Monique Wittig, “Combat por la libération de la femme" e Chrsitine Delphy, "L'ennemi principal", na medida em que nestes se lê a urgência de formação de um movimento de libertação das mulheres numa perspectiva revolucionária. No seio desta tendência, os grupos lésbicos consideram necessário um separatismo radical para lutar contra toda a coacção à heterossexualidade. Em 1973, num artigo da revista Le Nouvel Observateur intitulado "Le Mlf c'est toi, c'est moi" é enunciado um testemunho, que ilustra o pensamento da facção mais radical das feministas revolucionárias, o das “Gouines Rouges" ["Fufas Vermelhas”]. ${ }^{21}$

À pergunta: “L'homosexualité est-elle révolutionnaire? Monique - que se suspeita ser Wittig - responde:

Ce qui nous intéresse, c'est le déclenchement d'une nouvelle culture. Le monde doit être repensé en termes complètement différents. Si l'on veut éviter de se définir par rapport aux hommes, il est plus facile de commencer par se couper d'eux. Qu'est-ce que le principe masculin? Le principe féminin? Il y a en nous le désir d'une nouvelle femme, qui ne serait ni femme ni homme. Je pense à l'Amazone, celle qui réunit les deux sexes (Muchnick 1973: 64). ${ }^{22}$

Assim, para as feministas radicais a libertação das mulheres depende da abolição das categorias de género e da subsequente criação de um género-neutro universal onde em última análise os conceitos de "homem" e "mulher" se tornariam irrelevantes para a nossa existência enquanto ser humano (Wittig 2001). Esta tendência seria hoje denominada, não como revolucionária, mas "construcionista".

Do lado oposto, a tendência "diferencialista" (também denominada "essencialista" pelos seus detractores) argumenta que a tarefa mais importante para as mulheres é a de reivindicar a sua diferença, não aceitando o constructo patriarcal da "feminilidade", como 
uma versão inferior da "masculinidade", mas através da criação de identidades específicas em harmonia com as suas experiências de mulheres. Luce Irigaray defende particularmente que os homens e as mulheres devem desenvolver subjectividades diferentes, caso contrário a mulher continuará submetida à categoria masculina "homem" como tem ocorrido ao longo da história do patriarcado (Irigaray 1974: 48).

A caracterização que se segue da tendência feminista revolucionária, apesar de correr um risco de reducionismo - temido pelas suas próprias activistas - pretende dar a ver o terreno político, cultural, feminista e ideológico que favoreceu o acolhimento do livro em França. Para Françoise Picq, a força das feministas revolucionárias reside no humor corrosivo e irreverente que manifestam e no gosto pelas acções espectaculares que falam por si mesmas e sobre as quais a imprensa fala. "La grande force des Féministes révolutionnaires, c'est l'humour. Un humour corrosif, créatif, décapant. (...) Mettent d'instinct le doigt sur les questions sensibles, brûlantes. Elles manient la dérision, certaines avec beaucoup de talent, et gardent l'esprit critique, y compris par rapport à elles mêmes" (Picq 1993: 199). Dominique Poggi sublinha que a grande energia das acções levadas a cabo pelas FR provém de uma dimensão criativa e artística, da qual o espectáculo "La nuit des femmes" e a "procissão" nocturna diante da catedral de Notre-Dame de Paris, duas das três acções de apoio às Três Marias, em França, fazem prova. ${ }^{23}$

"La nuit des femmes" é uma leitura-espectáculo dirigida por Gilda Grillo, encenadora e fotógrafa brasileira, exilada na época em Paris, signatária do abaixo-assinado de apoio às "Três Marias", entregue na Embaixada de Portugal em Paris a 3 de Julho de 1973. O espectáculo que constava da leitura de excertos das Novas Cartas Portuguesas, conta com a participação das actrizes Delphine Seyrig, Isabel Ehni (cujo nome consta no abaixo-assinado entregue na Embaixada de Portugal em Paris) e Ruth Escobar, encenadora e actriz, brasileira de origem portuguesa, que na época tinha trazido a Cascais o espectáculo “Cemitério de automóveis"24, censurado no Brasil. Na leitura-espectáculo realizada a 21 de Outubro de 1973, na sala Gémier do Palais de Chaillot, para além das celebridades provenientes de um meio artístico como as actrizes referidas ou Ricky Dassin, compositora, irmã de Joe Dassin, participam militantes feministas, ligadas às revolucionárias, como as já 
referidas Dominique Poggi e Monique Bourroux. Aliás, na bio-bibliografia elaborada por Marie-Hélène Bourcier, para a edição de Parce que les lesbiennes ne sont pas des femmes... que consiste nas actas do colóquio sobre a obra política, teórica e literária de Monique Wittig, realizado em Paris na Columbia University, em Junho de 2001, lê-se que "La Nuit des femmes" foi organizada especificamente pelas feministas revolucionárias.

Na sala Gémier do Teatro Nacional de Chaillot, com capacidade para 600 pessoas, superlotada de mulheres, foi negada a entrada aos homens, sendo assim praticada a reivindicação de um movimento de libertação não misto, que recusava aos homens o direito de falarem em nome das mulheres, tal como tinha sido desejado em Vincennes desde a primeira manifestação, em Maio de 1970. As mulheres deviam separar-se dos homens para analisar entre elas a opressão e determinar meios de luta sem a presença dos opressores.

Em contrapartida, a procissão com archotes no adro de Notre Dame torna-se um hapenning, onde não só as participantes desfilam com uma indumentária adequada à celebração, algumas vestidas de negro, com xailes, archotes e velas, mas também cantam a ária de Dies Irae (Dia de Ira), com letra obviamente adaptada à situação. Note-se que a adaptação de novas letras a músicas conhecidas, era uma prática corrente nas manifestações feministas. As letras inventadas diziam obviamente respeito às causas reivindicadas e, segundo diversos testemunhos, Christiane Rochefort era uma especialista na adaptação de novas letras a árias clássicas e tradicionais. A encenação desta "procissão" sugere uma caça às bruxas. A música e as efígies das escritoras em andores podem ser interpretadas como uma sátira ou apenas referência ao contexto católico determinante da figura inspiradora do livro, a freira de Beja, Mariana Alcoforado. A atmosfera ditatorial e inquisitória, implícita e explicitamente criticada nas Novas Cartas Portuguesas, é reconfigurada, de forma inversa, através de um desfile de mulheres vestidas de negro - cor das viúvas e das "beatas" - que diante da Catedral de Notre-Dame, entoam um cântico maléfico aos perseguidores das "Três Marias". O tom do cântico evoca as feiticeiras perseguidas, que nesta encenação encarnada pelas feministas parisienses desafia e ameaça os perseguidores. Esta manifestação inverte os papéis do processo, as mulheres/ "bruxas", de acusadas e perseguidas passam a risonhas acusadoras. 
A constituição de grupos não mistos, desencadeia uma tomada de consciência sobre as condições das mulheres que lhes permite encontrar uma força identitária através da análise dos seus problemas íntimos, observados assim não como problemas individuais, mas de classe. Os chamados grupos de "prise de conscience", compostos por seis ou sete mulheres que encontram, assim, um lugar para a sua palavra, desempenham um papel fundamental na força inerente ao movimento. É precisamente a um destes grupos que chega o livro enviado a Christiane Rochefort. Carmen Sanchez, que vivia na mesma casa, descobre o livro e a carta que o acompanha no meio da correspondência da escritora, num momento em que esta não se encontrava em Paris ${ }^{25}$ e dá-os a conhecer ao seu grupo de tomada de consciência, do qual faziam parte Monique Wittig e Dominique Poggi. ${ }^{26}$

Gilda Grillo também refere a sua participação no que designa por "group of self consciousness" ou "consciousness raising" uma vez que reunia com feministas anglófonas residentes em Paris. No já referido artigo do Nouvel Observateur de 27 de Agosto de 1973, intitulado "Le M.L.F., c'est toi, c'est moi", lê-se ainda o seguinte testemunho sobre esta estratégia, adoptada com o objectivo de permitir a expressão espontânea, eliminando "dirigismos" e vontades de poder no seio do movimento: "Dans une réunion de quinze personnes, dit Monique, la parole est déjà institutionnalisée: ne parlent que celles qui savent. À cinq ou six, cela ne se produit jamais. Le groupe sape à la base tout leadership, et aussi récupère l'énergie des femmes" (Muchnick 1973: 63).

Valorizando a espontaneidade e a livre expressão de cada uma, as feministas revolucionárias olham com desconfiança aquelas que têm um desejo ou a capacidade de se exprimir em nome das outras, suspeitando nessa atitude um desejo de poder. Esta é razão principal pela qual o funcionamento de "Psychanalyse et Politique" lhes desagrada. (Picq 1993: 200). ${ }^{27}$ O protagonismo de Antoinette Fouque incomoda-as. A esta desconfiança da vontade de poder, associa-se a rejeição de qualquer sistema de organização hierárquica. 0 que caracteriza o movimento no seu início é a originalidade de se inventar através do encontro espontâneo entre mulheres, numa democracia directa, sem que haja qualquer intenção de representação. 0 movimento era habitado por uma preocupação intrínseca de deixar cada uma falar por si e não pelas outras. Numa dinâmica anti-autoritária, pertencer 
ao movimento significava fazer parte de uma nova ideologia: a da "sororité" (FougeyrollasSchwebel 2000: 127).

Com a intenção de permitir a emergência e a visibilidade da sororidade, as militantes, quando escrevem, dão preferência aos textos colectivos e anónimos, o que nos reenvia para a tecedura de Novas Cartas Portuguesas. No já referido primeiro jornal do movimento de libertação das mulheres, Le torchon brûle, publicado entre 1970 e 1973 os artigos não são assinados. Do mesmo modo, na obra colectiva Le livre de l'oppression des femmes, publicada em 1972, os textos também não são assinados, sabendo-se apenas que são da autoria de um colectivo de nomes próprios, do qual se adivinha, por exemplo, que Christiane, seja Rochefort e que Gillou, seja Gilles Wittig. No número especial da revista Partisans do outono de 1970 são também poucas as assinaturas individuais, e as que se identificam utilizam frequentemente apenas o nome próprio ou um pseudónimo, como é o caso de Christine Delphy, que assina Christine Dupont (cf. supra). ${ }^{28}$ Algumas destas publicações para além de serem anónimas não respeitam qualquer subordinação a um género literário, o que evoca ainda as Novas Cartas Portuguesas. Tal como na colectânea Sisterhood is powerful, publicada em 1970 se pode ler desde a poesia de Sylvia Plath, a documentos históricos da NOW ou excertos do Manifesto de Valerie Solanas SCUM (Society for Cutting up Men), encontram-se assim misturados, nestas miscelâneas francesas, textos teóricos, panfletários e poéticos.

É precisamente em Outubro de 1973, no mesmo mês em que ocorre em Lisboa a primeira audiência do julgamento das três autoras, acusadas de escreverem um livro "pornográfico" e "atentatório da moral pública", que em Paris a "directora da publicação"29 do jornal do MLF, Le Torchon Brûle, é acusada de "outrage aux bonnes moeurs" [atentado à moral pública]. 0 artigo que despoleta a acusação sai no segundo número do jornal e intitula-se: "Le pouvoir du con" ["O poder da cona”]. Uma vez que nenhum artigo deste jornal era assinado individualmente, e que a sua realização era da responsabilidade colectiva, não houve qualquer condenação, mas uma ilibação por anonimato. Resolução que lembra ainda a resistência das escritoras das Novas Cartas Portuguesas em revelar a autoria destas. 
Assim era em 1973, a escrita colectiva das mulheres julgada em tribunal, tanto num regime ditatorial como num regime democrático. Apesar das devidas diferenças, vivia-se há quarenta anos, tanto no centro da Europa, como na sua periferia, tal como ainda hoje, uma opressão sobre as mulheres que justificava e continua a justificar a reivindicação de direitos e a solidariedade fundamental entre elas.

\section{NOTAS}

${ }^{1}$ Entrevista a Gilda Grillo, realizada por Skype, a 17 de Janeiro de 2014.

2 Encontrei este abaixo-assinado, de cinco páginas, no Arquivo Histórico-Diplomático do Ministério dos Negócios Estrangeiros em Lisboa a 28 de Outubro de 2013, na Pasta 3: “O caso das “Três Marias” (Maria Isabel BARRENO, Maria Fátima Velho da COSTA e Maria Teresa HORTA, autoras das "Novas Cartas Portuguesas")», com a cota: PEA (4) M 743 Proc. 316.1. Ao texto referido, seguem-se uma lista de nomes e várias assinaturas, que nem sempre coincidem, ou seja há nomes que não aparecem assinados e assinaturas que não constam da lista de nomes. Note-se que os nomes de Simone de Beauvoir e Marguerite Duras integram a lista dos nomes, no entanto não aparecem na série de assinaturas.

3 Este vídeo, propriedade do Centre Audiovisuel Simone de Beauvoir em Paris fundado em 1982, pelas militantes feministas e realizadoras Carole Roussopolous, Delphine Seyrig e Iona Wieder, pode ser actualmente visionado em suporte VHS, sob marcação, neste mesmo centro de pesquisa audiovisual.

${ }^{4} \mathrm{O}$ acesso a estas fotografias foi-me directamente facultado pela sua autora, durante a entrevista realizada a 29 de Janeiro de 2014, em Paris.

5 <http://re-belles.over-blog.com/article-ag-de-l-association-40-ans-de-mouvement-76426370.html> (último acesso em 07/05/2016).

${ }^{6}$ Neste mesmo mês terá lugar na Universidade de Vincennes uma manifestação na qual, pela primeira vez, se vêem em cartazes e faixas a frase: “Libération des femmes, année 0". 
${ }^{7}$ A 26 de Agosto de 1970, cinquenta anos depois de adquirido o direito de voto feminin o nos Estados Unidos, as americanas fazem greve: do trabalho doméstico, do cuidar das crianças, da cama...

L'explosion étudiante de l'année 1968 est le terreau de la diffusion du féminisme, et la grande apparition publique du mouvement américain le 26 août 1970, pour fêter les cinquante ans du droit de vote aux États-Unis, donne force aux mouvements européens. (...) Ce sont d'abord les campagnes pour la liberté d'avorter qui constituent les événements plus importants et les plus marquants. Apparaissent également des mobilisations contre les violences faites aux femmes - viol, harcèlement sexuel - et la transformation du droit : la reconnaissance du viol conjugale. (Fougeyrollas-Schwebel 2000: 128)

80 singular "la femme" sempre foi recusado pelo movimento de libertação que era considerado de todas "as mulheres". "Le lendemain, L'Aurore et le Figaro annoncent la naissance du "Mouvement de libération de la (sic) femme française (re-sic)." (Delphy 1991: 143).

${ }^{9}$ A partir do Outono de 1970 um "grupo aborto" forma-se no seio do MLF e reúne-se todas as quintas-feiras na Escola de Belas-Artes de Paris. Lugar que acolhe as reuniões do movimento feminista. Neste grupo encontram-se Delphy e Zelenski (Pisan / Tristan 1977: 65). Rapidamente jornalistas do Nouvel Observateur, Jean Moureau e Nicole Muchnick, que seguem e apoiam as acções do MLF, propõem-lhes a publicação do manifesto. Duas jornalistas, Nicole Muchnick e Michele Manceaux, que dirigem o inquérito sobre o aborto publicado no mesmo no do Nouvel Observateur de 5 de abril de 1971, também assinam o manifesto.

10 Christine Delphy, socióloga, é investigadora no CNRS (Centre National de Recherche Scientifique), no domínio dos estudos feministas, desde 1966, e fundadora de Questions Féministes e de Nouvelles Questions féministes, revista que introduz o feminismo materialista e as questões de género em França.

11 Delphy assina, na época, o artigo "L'ennemi principal" publicado no n. - 54-55 da revista Partisans com o pseudónimo de Dupont. Dois anos mais tarde, na edição de bolso de Libération des femmes année zero, Rochefort e Delphy, de acordo com a "ideologia" vigente, assinam apenas com o nome próprio, como rejeição simbólica do nome do pai ou do marido, mesmo sob a forma de pseudónimo.

12 Entrevista concedida por Maria Teresa Horta a 29 de Outubro de 2013.

13 "Nós não conhecíamos as escritoras, de tal maneira que mandamos as cartas com o livro para as editoras delas. A Teresa escolheu a Simone de Beauvoir como tinha escrito Deuxième sexe interessava-se directamente pelo assunto. A Fátima escolheu a Marguerite Duras por ser uma escritora de qualidade. Eu escolhi a Christiane Rochefort apesar de ser uma escritora de segundo plano, porque sabia que ela estava ligada aos grupos feministas e, aliás, foi o contacto de Christiane Rochefort que veio a desencadear todo o processo" (Coutinho et al, 2003: 67). 
${ }^{14}$ Carmen Sanchez é uma peruana, que depois de ter passado pela Suécia, se fixou em Paris em 1970, tendo participado activamente nas acções do MLF desde as suas origens.

15 Depois de um primeiro contacto com Dominique Poggi, foi possível organizar o visionamento do filme "Les trois portugaises" em casa de Josy Thibaut, que gentilmente nos recebeu, na companhia de Carmen Sanchez, Catherine Deudon e Dominique Poggi, a 17 de Dezembro de 2013.

${ }^{16}$ Depois de um primeiro contacto com Dominique Poggi, foi possível organizar o visionamento do filme "Les trois portugaises" em casa de Josy Thibaut, que gentilmente nos recebeu, na companhia de Carmen Sanchez, Catherine Deudon e Dominique Poggi, a 17 de Dezembro de 2013.

17 Algumas das militantes, presentes nas fotografias, foram identificadas pela fotógrafa, psiquiatra, Irene Bouaziz, na entrevista concedida a 29 de Janeiro de 2014.

${ }^{18}$ Entre outras, para além das acções já referidas, as feministas revolucionárias implicam-se no manifesto das 343 (Abril 1971), organizam as Jornadas de denúncia dos crimes cometidos contra as mulheres (Maio de 1972) e a Feira das Mulheres a 17 de Junho de 1973, na Cartoucherie de Vincennes. Será graças aos cinco mil bilhetes vendidos para esta festa que conseguem alugar um local reservado ao movimento, na Cité Trévise.

19 Publicado em 1993 com o título: "Libération des femmes : les années-mouvement" e reeditado em 2011, com o título "Libération des femmes 40 ans de mouvement".

20 O grupo FMA (Féminin, Masculin, Avenir) constituído por Anne Zelenski e Jacqueline Feldman - colegas no seminário de Andrée Michel -, existe desde 1967, juntando-se-lhes em 1968, Christine Delphy e Emmanuelle de Lesseps. Este grupo que no início era misto, torna-se não misto e passa a significar (Féminisme, Marxisme, Action). Posteriormente Monique Wittig e as consignatárias de «Combat pour la libération de la femme», dissidentes do grupo que tinham formado com Antoinette Fouque e Josianne Chanel, jun tam-se aos membros do FMA, aderindo às posições defendidas por Christine Delphy no artigo "L'ennemi principal”, acreditando que as mulheres formam, para lá da diferença de classe, uma mesma categoria, um grupo social definido por uma exploração doméstica comum.

${ }^{21}$ Les homosexuelles ont une culture et une lutte spécifique à mener au sein du Mouvement, déclarent les Gouines rouges, annonçant des réunions sur "Lesbianisme et féminisme" en janvier 1974. Elles se considèrent volontiers comme les seules pures et dures, celles qui ne pactisent pas avec l'ennemi. (...) C'est aussi un comportement culturel : vivre par soi, pour soi, en dehors du regard des hommes, du monde qu'ils ont construit. De fait, le Mouvement tout entier fonctionne comme un groupe homosocial. Il exclut les hommes et forge la culture des femmes dans la communication affective entre elles. (...) Du haut de leur radicalité, des homosexuelles jaugent l'engagement des autres femmes : “On ne peut pas être vraiment féministe et vraiment aimer les hommes." (Picq 2011: 236-237).

N.ㅇ 35 - 12/ 2016 | 225-246 - ISSN 1645-1112 | http:/dx.doi.org/10.21747/16451112/litcomp35a12 
22 Note-se que Monique Wittig publica neste mesmo ano de 1973 Le corps lesbien, tendo publicado em 1969, Les Guérillères, cujo título não deixa de evocar as Amazonas.

${ }^{23}$ Entrevista realizada a Dominique Poggi, em Paris no café de "La Halle Saint-Pierre, a 16 de Novembro de 2013.

${ }^{24}$ Como se pode ler na entrevista de Ruth Escobar publicada no livro Brasileiras, esta actriz desenvolveu uma admiração imensa pela obra que lhe foi comunicada por Gilda Grillo. Aliás, a fotografia famosa das três escritoras, que faz cartaz de colóquios e capa de livros, foi tirada por Gilda Grillo, segundo o testemunho de Maria Teresa Horta, na casa alugada em Cascais por Ruth Escobar, quando veio com a sua companhia apresentar a peça, “Cemitério de automóveis", encenada por Victor Garcia, a partir do texto de Arrabal, num barracão da Avenida da República em Cascais, no Verão de 1973.

25 Em 1973, Christiane Rochefort é convidada oficialmente para ir aos Estados Unidos. "1973 - Invitée officiellement aux USA. New York et Montréal deviendront ses patries de cœur." (Sagaert 2004: 1490).

${ }^{26}$ Entrevistas concedidas por Dominique Poggi, a 16 de Novembro de 2013 e por Carmen Sanchez, a 17 de Dezembro de 2013.

${ }^{27}$ A propósito dos grupos de consciência e da «organização espontânea» sem dirigismos, consultar os textos sobre a Libertação das Mulheres nos Estados Unidos que abrem o número especial da revista Partisans, de outubro de 1970.

28 Enquanto uma grande parte das feministas reivindicava, na época, o anonimato e uma assinatura colectiva, Christiane Rochefort considerava que cada uma devia assinar e reivindicar pessoalmente os textos que escrevia, para que fossem perceptíveis as eventuais mudanças e evoluções no pensamento individual. Respeitando as decisões colectivas, Rochefort aceita a regra do anonimato, tentando no entanto que esta fosse abandonada. (Bernheim et al 2009: 49).

${ }^{29}$ Marie Dedieu nunca foi realmente directora do jornal, na medida em que as equipas de produção de cada número eram diferentes e não tinham ninguém a dirigi-las. A direcção de publicação em nome de Marie Dedieu serviu apenas para que em termos legais este pudesse ser vendido. 


\section{Bibliografia}

AVV (1972), Le livre de l'oppression des femmes, Paris, P. Belfond.

Barreno, Maria Isabel/ Maria Teresa Horta/Maria Velho da Costa (2010), Novas Cartas Portuguesas, Edição Anotada, Org. Ana Luísa Amaral, Lisboa, Publicações Dom Quixote [1972].

Bernheim, Cathy et al. (2009), Mouvement de Libération des femmes: textes premiers, Paris, Stock.

Bourcier, Marie-Hélène / Suzette Robichon (2002), Parce que les lesbiennes ne sont pas des femmes..., Paris, Ed. Gaies et Lesbiennes.

Coutinho, Cláudia et al. (2003), “Conversa com Maria Isabel Barreno", Textos e Pretextos: Maria Velho da Costa, n.ㅇ 3, Lisboa, Centro de Estudos Comparatistas da Faculdade de Letras da Universidade de Lisboa, 64-68.

Delphy, Christine (1991), "Les origines du Mouvement de Libération des Femmes en France", Nouvelles Questions Féministes, n.ำ 16 -17-18, 137-147.

Fougeyrollas-Schwebel, Dominique (2000), "Mouvements féministes", in Dictionnaire critique du féminisme, Paris, Presses universitaires de France, 125- 130.

Fouque, Antoinette (org.) (2008), Génération MLF: 1968-2008, Paris, Des Femmes - A. Fouque.

Irigaray, Luce (1974), Speculum, de l'autre femme, Paris, Minuit.

Lapouge, Maryvonne/ Clélia Pisa (1977), «Ruth Escobar», Brasileiras: Voix, écrits du Brésil. Paris, Des Femmes.

Le Garrec, Évelyne / Monique Wittig (1974), “Note pour l'édition française”, in Nouvelles Lettres Portugaises, Paris, Du Seuil: 7-11. 
Para uma genealogia da recepção de Novas Cartas Portuguesas em França

Le Nouvel Observateur (1974), «Les trois Maria», 4 février, p. 26. $<$ http://www.novascartasnovas.com/multimedia.html> (último acesso 11/05/2016).

Morgan, Robin (org.) (1970), Sisterhood is powerful: an anthology of writings from the women's liberation movement, New York, Vintage Books.

Muchnick, Nicole (1973), "Le MLF c'est toi, c'est moi”, Le Nouvel Observateur, 27 août, 5464.

Partisans : Libération des femmes année zero (1970), no 54-55, Paris, François Maspéro.

Partisans : Libération des femmes année zero (1972), Paris, François Maspéro.

Pavard, Bibia (2012), Si je veux, quand je veux: contraception et avortement dans la société française, 1956-1979, Rennes, Presses universitaires de Rennes.

Pisan, Annie / Anne Tristan, (1977), Histoires du MLF, Paris, Calman-Lévy.

Picq, Françoise (1993), Libération des femmes : les années-mouvement, Paris, Éditions du Seuil.

--, (2011), Libération des femmes, 40 ans de mouvement, Brest, Éditions-dialogues.fr.

Sagaert, Martine (2004), "Chrono-Biographie", in Oeuvre Romanesque de Christiane de Rochefort, Paris, Grasset.

Wittig, Monique (2001), La pensée straight, Paris, Balland.

Wittig, Monique et al. (1970), "Combat pour la libération de la femme”, L'Idiot International, n.. 6, mai, 10-14. 
Adília Martins de Carvalho é actualmente leitora do Camões, I.P., na Universidade do Luxemburgo, sendo doutorada pelas Universidades Nova de Lisboa e Universidade Sorbonne Nouvelle - Paris 3, com uma dissertação intitulada "Leitura das Margens nas obras de Maria Velho da Costa e Teolinda Gersão". Integrou a equipa francesa do projecto "Novas Cartas Portuguesas - 40 anos depois" e desenvolveu pesquisa de pós-doutoramento nesse âmbito, sendo bolseira da FCT. Faz parte do grupo "Intersexualidades", que integra o projecto Literatura e Fronteiras do Conhecimento: Políticas de Inclusão, do Instituto de Literatura Comparada Margarida Losa da Universidade do Porto. 